Article

\title{
Analysis and Optimization of Spiral Circular Inductive Coupling Link for Bio-Implanted Applications on Air and within Human Tissue
}

\author{
Saad Mutashar ${ }^{1,2, *}$, Mahammad A. Hannan ${ }^{1}$, Salina A. Samad ${ }^{1}$ and Aini Hussain ${ }^{1}$ \\ 1 Department of Electrical, Electronic \& Systems Engineering, Faculty of Engineering and Built \\ Environment, Universiti Kebangsaan Malaysia, 43600 UKM Bangi Selangor, Malaysia; \\ E-Mails: hannan@eng.ukm.my (M.A.H.); salina@eng.ukm.my (S.A.S.); aini@eng.ukm.my (A.H.) \\ 2 Department of Electrical and Electronic Engineering, University of Technology-Iraq, \\ 35010 Baghdad, Iraq \\ * Author to whom correspondence should be addressed; E-Mail: saad_ra25@yahoo.com; \\ Tel.: +60-176-870-253.
}

Received: 1 May 2014; in revised form: 19 June 2014 / Accepted: 26 June 2014 /

Published: 30 June 2014

\begin{abstract}
The use of wireless communication using inductive links to transfer data and power to implantable microsystems to stimulate and monitor nerves and muscles is increasing. This paper deals with the development of the theoretical analysis and optimization of an inductive link based on coupling and on spiral circular coil geometry. The coil dimensions offer $22 \mathrm{~mm}$ of mutual distance in air. However, at $6 \mathrm{~mm}$ of distance, the coils offer a power transmission efficiency of $80 \%$ in the optimum case and $73 \%$ in the worst case via low input impedance, whereas, transmission efficiency is $45 \%$ and $32 \%$, respectively, via high input impedance. The simulations were performed in air and with two types of simulated human biological tissues such as dry and wet-skin using a depth of $6 \mathrm{~mm}$. The performance results expound that the combined magnitude of the electric field components surrounding the external coil is approximately $98 \%$ of that in air, and for an internal coil, it is approximately 50\%, respectively. It can be seen that the gain surrounding coils is almost constant and confirms the omnidirectional pattern associated with such loop antennas which reduces the effect of non-alignment between the two coils. The results also show that the specific absorption rate (SAR) and power loss within the tissue are lower than that of the standard level. Thus, the tissue will not be damaged anymore.
\end{abstract}


Keywords: bio-medical implanted devices; ISM band; inductive coupling link spiral coils; SAR effect

\section{Introduction}

The reduction of patient discomfort and risk of infection is the main design concern in the implanted device field. Recently, most bio-implantable devices are powered using implanted batteries, resulting skin infections and hazards. Because the implanted batteries have chemical side effects and limited lifetime, researchers have developed a safer alternative method for powering implantable devices using inductive power links. The magnetic inductive link approach is believed to be the most promising technique for implantable devices. Its advantages include continuous availability of high levels of power to an implanted device, and the ability to control it with the external device using the magnetic link. In addition, the lifetime and shelf life of the implanted devices are not restricted by the lifetime of a battery. Hence, it can be used for long term and during the patient's activities [1]

Bio-implantable devices designed with the smallest possible size are to be implanted depending on functional depth in the human biological tissue, which is usually less than $10 \mathrm{~mm}$ of depth. For example, in general implanted micro-system stimulators depth is $1-4 \mathrm{~mm}$, for retinal implants it is $5 \mathrm{~mm}$ and for cochlear implants depth is $3-6 \mathrm{~mm}$, respectively [2-4]. The inductive powering links method is a suitable method for powering implanted devices. This inductive coupling link consists of two $R L C$ circuits, acting as a transmitter and receiver coils. To obtain better power transfer efficiency (PTE), both $R L C$ circuits are tuned to the same resonant frequency $\omega_{0}$. The external $R L C$ circuit fixed outside the body is tuned to the serial resonance to provide a low-impedance load to deliver maximum power from the source to the implanted circuit. The internal $R L C$ circuit is implanted within the body and tuned to the parallel resonance to improve the driving performance for remote load resistance [5-7]. Many design issues should be considered such as patient comfort, endurance portability, reliability, size, power consumption and feasibility.

Most implanted microsystems are used to stimulate and monitor biological signals in the near field region such as nerves and muscle activities. In addition, the development of implanted microsystems will helps biological research to recognize and develop treatments for nerve diseases such as brain disorders i.e., epilepsy, stroke and paralysis. Power transmission is the key in designing such bio-implantable devices. The power transfer efficiency is affected by the coil parameters, including their lumped elements such as parasitic resistance and capacitance associated with them, geometries, alignments, and distance between coils.

The mutual distance between the transmitter (external) and receiver (implant) coils is to be smaller than the wavelength in the near field, which depends on the coil dimensions. Hence, the coil dimensions have a direct effect on the distance and a coupling link which consists of two differing or same-sized coils, oriented face-to-face. The external coil located outside the body can be accurate with flexibility in the design in terms of size, while the implanted coil located within the human body should be as small as possible. The implanted coil is the main reason for the power consumption, therefore; it should be carefully designed in terms of shape and geometry. The coupling increases as 
the coil dimensions increase and as the distance between the coils decreases. To provide a coupling link at $10 \mathrm{~mm}$, a spiral rectangular coil shape with external and internal dimensions of $62 \mathrm{~mm} \times 25 \mathrm{~mm}$ and $25 \mathrm{~mm} \times 10 \mathrm{~mm}$ was designed at $13.56 \mathrm{MHz}$. In this design, the relative short-range coupling and implanted coil size are the issues [8].

A spiral square coil shape with outer and inner dimensions of $70 \mathrm{~mm} \times 8 \mathrm{~mm}$ and $20 \mathrm{~mm} \times 8 \mathrm{~mm}$ was designed for $1 \mathrm{MHz}$ to $5 \mathrm{MHz}$ frequency ranges. It is seen that the design provides optimum coupling at a distance of $10 \mathrm{~mm}$; however, for better performance, the size and relative short-range coupling still need to be considered [9]. The coupling links between two circular coil dimensions $\mathrm{d}_{\text {out }}=38 \mathrm{~mm}$, $\mathrm{d}_{\text {in }}=36 \mathrm{~mm}$ and $\mathrm{d}_{\text {out }}=18 \mathrm{~mm}, \mathrm{~d}_{\text {in }}=16 \mathrm{~mm}$ was designed to offer $15 \mathrm{~mm}$ of distance coupling with an operating frequency of $742 \mathrm{KHz}$. However, this design will increase the printed board circuits and occupies a relatively large area within tissues [10]. For EEG signal detection, Sauer et al., designed a coupling link based on circular coils with external coil dimensions of $50 \mathrm{~mm}$ and an internal coil of $20 \mathrm{~mm}$ to offer $28 \mathrm{~mm}$ of distance with an operating frequency of $4 \mathrm{MHz}$, the implanted coil size is still the issue when it occupies a relatively large area [11].

Printed spiral circular coils (PSCCs) are robust against lateral misalignments and reliable for implantation under the skin. They can be fitted outside the body or within the epidural space. In this study, the reflected impedance concept analysis is optimized and modified to obtain efficient power transmission between two pairs of proposed single-layer planar spiral circular coils, which are printed on small substrate PCBs. Firstly, air separates the two coils. Then, a biological human tissue model with $6 \mathrm{~mm}$ of thickness is assumed as a medium between coils, which is considered as a relative distance between the coils. The tissue thickness of $6 \mathrm{~mm}$ is an appropriate depth, which is faithful to the distance used for implantable devices such as cochlear implants, implanted micro-systems and retinal implants [4]. The transmitter and receiver had the following respective external and internal dimensions: the outer and inner transmitter dimensions are $56 \mathrm{~mm}$ and $10 \mathrm{~mm}$, respectively, and for the receiver (implanted) coil they are $11.6 \mathrm{~mm}$ and $5 \mathrm{~mm}$, respectively. The circuit was designed to provide a $22 \mathrm{~mm}$ of coupling distance using the Industrial Specific Medical (ISM) operating frequency of $13.56 \mathrm{MHz}$. The distance of $22 \mathrm{~mm}$ is more than enough for our application because the proposed tissue thickness is no more than $6 \mathrm{~mm}$. The geometry of the coil values is recommended by theoretical calculations using MATLAB to establish the efficiency of the coils. The High Frequency Structure Simulator ANSOFT-HFSS-13.0 with finite element method (FEM) software in near-field is used to simulate and calculate the gain surrounding coils in air and within the tissue; it is also used to validate the coil design. The SEMCAD software used to calculate the SAR within tissue.

\section{Methods and Materials}

An inductive coupling link with serial to parallel topology is a suitable connection for biomedical applications. The theoretical analysis and simulation are very important in designing an ideal inductive coupling for estimating the received power. Different theoretical analysis methods have been investigated for solving and deriving the equations for calculating the received power of the implant device.

In this paper, the reflected impedance method is obtained by modifying the lumped equivalent circuit to quantify and optimize the power transmission efficiency between the two coils. The optimization is done when the input impedance is low and when the input impedance is high. The 
medium separating the coils is considered as air (free space) and biological human tissue separately. The simulated biological human tissue model included dry and wet skin having similar constitutive parameters to live human tissue.

\section{Analysis and Optimization Based on Coupling}

There are four different combinations of highly coupled stagger-tuned inductive links. They are: voltage in-voltage out, voltage in-current out, current in-current out and current in-voltage out. The "voltage in-voltage out" link is an approach which can control the output power. This approach is based on the coupling used to calculate and optimize the power transmission efficiency.

\subsection{Inductive Power Transmission Efficiency}

The inductive link with serial to parallel (SP) topology is the common part between the external and internal architectures which is the suitable topology to be used for subcutaneous implanted devices. Figure 1 shows the equivalent scheme of the SP topology that consists of two parts, external part (reader) and internal part (implant). The power transfer efficiency (PTE) is one of the major specifications for assessing the performance of an inductive link [12].

Figure 1. The inductive SP topology.

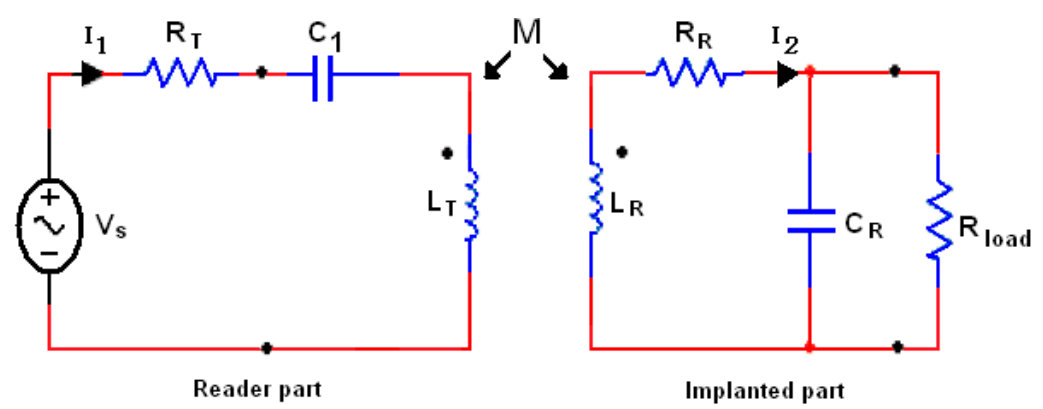

Figure 2 shows the lumped elements of the equivalent scheme, the resistance $R_{L T}$ and $R_{L R}$ are equivalent series resistors of inductors $L_{T}$ and $L_{R}$, respectively, and expressed as follows:

$$
\begin{gathered}
L_{T}=\frac{1}{C_{1} \omega_{0}^{2}} \\
L_{R}=\frac{1}{C_{2} \omega_{0}^{2}} \\
R_{L R}=\frac{R_{\text {load }}}{1+\omega_{0}^{2} R_{\text {load }}^{2} C_{R}^{2}}
\end{gathered}
$$

The parasitic resistor $R_{L T}$ is model the series resistance of one turn of the inductance. This resistor also included the reflected back resistor into the transmitter which is very small and can be ignored. $M$ is the mutual inductance between the transmitter inductance $L_{T}$ and receiver inductance $L_{R}$. The primary coil driven by the efficient power amplifier, which is modeled as a voltage source and having a series resistance $\mathrm{R}_{\mathrm{P}}$. 
Figure 2. Inductive power link schematic and its equivalent circuit.

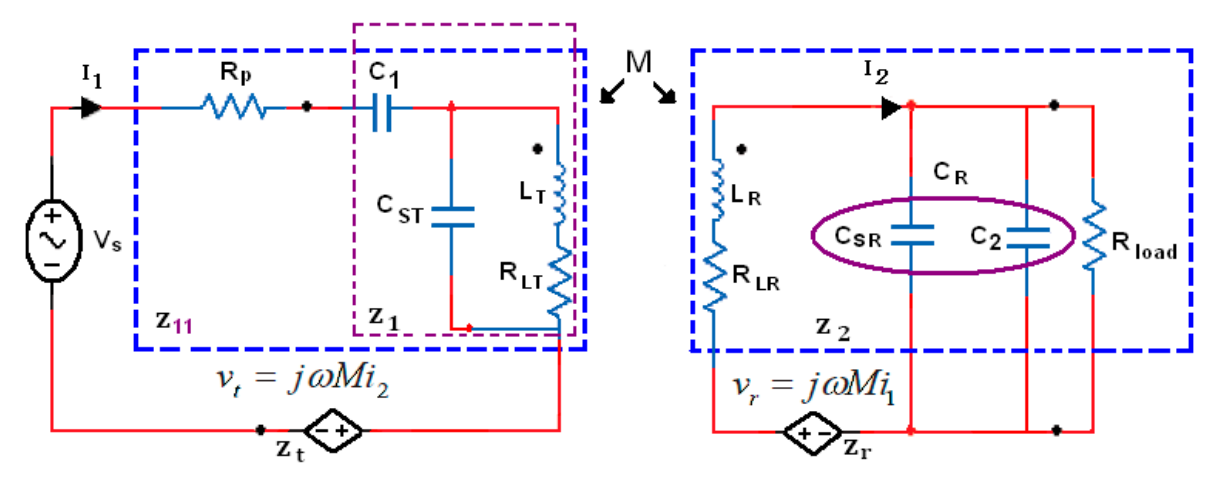

The coil windings have umped elements, such as parasitic resistance and capacitance associated with them. The transmitter and receiver coil lumped elements are $\mathrm{R}_{\mathrm{LT}}, \mathrm{C}_{\mathrm{ST}}$ and $\mathrm{R}_{\mathrm{LR}}, \mathrm{C}_{\mathrm{SR}}$, respectively. The capacitors $C_{1}$ and $C_{2}$ are added to form the resonant $L C$-tank circuits for the conductors $L_{T}$ and $L_{R}$, respectively, and should be chosen to approximately have the same values. $\mathrm{R}_{\text {load }}$ represents the load resistance, and for the simplest analysis, $C_{R}=C_{S R}+C_{2}$. The efficient power transmission is calculated by using reflected impedance concept analysis from the receiver and transmitter, $\left(Z_{t}\right.$ and $\left.Z_{r}\right)$ as given in Equations (4)-(7):

$$
\begin{gathered}
Z_{t}=\frac{v_{t}}{I_{1}}=\frac{\omega^{2} M^{2}}{Z_{2}} \\
Z_{r}=\frac{v_{r}}{I_{2}}=j \omega M \frac{I_{1}}{I_{2}} \\
Z_{1}=\left(R_{L T}+j \omega L_{T} / / \frac{1}{j \omega C_{S T}}\right)+\frac{1}{j \omega C_{1}} \\
Z_{2}=R_{L R}+j \omega L_{R}+\frac{1}{j \omega C_{R}} / / R_{\text {load }}
\end{gathered}
$$

where $Z_{1}$ and $Z_{2}$ represent the impedance network for the transmitter and receiver including real and imaginary parts. The power transmitter efficiency (defined as the ratio of power consumed by the secondary circuits over the total power drained from the power supply source $\eta_{\mathrm{T}}$ ) and the power receiver efficiency (defined as the ratio of power consumed by the load $\mathrm{R}_{\text {load }}$ over the total power consumed at the implanted side $\eta_{\mathrm{R}}$ ) as given in Equations (8) and (9), respectively:

$$
\begin{gathered}
\eta_{T}=\left|\frac{Z_{t}}{Z_{1}+Z_{t}}\right| \leqq \frac{K^{2} Q_{1} Q_{2} R_{\text {load }}}{K^{2} Q_{1} Q_{2} R_{\text {load }}+Q_{2}^{2} R_{L R}} \\
\eta_{R}=\left|1-\frac{R_{L R}}{Z_{2}}\right| \leqq \frac{Q_{2}^{2} R_{L R}}{Q_{2}^{2} R_{L R}+R_{\text {load }}}
\end{gathered}
$$

Then total link efficiency is $\eta_{\text {link }}=\eta_{T} * \eta_{R}$, where total link efficiency $\eta_{\text {link }}$ reaches its maximum if $\mathrm{Z}_{1}$ and $\mathrm{Z}_{2}$ has only the real part left where the imaginary part is approximately zero; $\mathrm{Q}_{1}$ and $\mathrm{Q}_{2}$ represent the quality factors of transmitter and receiver coils as follows:

$$
Q_{1}=\frac{\omega_{0} L_{T}}{R_{L T}}
$$




$$
Q_{2}=\frac{\omega_{0} L_{R}}{R_{L R}}
$$

Both coils tuned at the same resonant frequency as given in Equation (12):

$$
\omega=\omega_{0}=\frac{1}{\left(L_{T} C_{1}\right)^{\frac{1}{2}}}=\frac{1}{\left(L_{R} C_{R}\right)^{\frac{1}{2}}}
$$

The coupling coefficient value is $(0<\mathrm{K}<1)$ depends on the coils' radius and is calculated as given in the coil optimization section. The implanted load resistance $R_{\text {load }}$, is calculated according to [13], as expressed in Equation (13):

$$
R_{\text {load }}-4 \omega^{2} L_{R}^{2}>0 \text { where } \omega=2 \pi f \text { and } \mathrm{R}_{\text {load }} \geq 2 \omega \mathrm{L}_{\mathrm{R}}
$$

where hence the $\mathrm{R}_{\text {load }} \geq 170 \Omega$, in our calculation we assume the $\mathrm{R}_{\text {load }}$ values are $200 \Omega$ to $400 \Omega$ by $50 \Omega$ steps, where $200 \Omega$ presents the worst case and $400 \Omega$ is an optimum case. The total efficiency is a product of $\eta_{T}$ and $\eta_{R}$ as illustrated in Equation (14):

$$
\eta_{\text {total }}=\eta_{T} \eta_{R}=\frac{K^{2} Q_{1} Q_{2}^{3} R_{L R} R_{\text {load }}}{\left(K^{2} Q_{1} Q_{2}^{3} R_{L R} R_{\text {load }}+K^{2} Q_{1} Q_{2} R_{\text {load }}^{2}+Q_{2}^{4} R_{L R}^{2}+2 Q_{2}^{2} R_{L R} R_{\text {load }}+R_{\text {load }}^{2}\right)}
$$

The efficiency given in Equation (14) is perfect and appropriate in the absence of resistance of the power amplifier, source and the low external circuit impedance. The inductive coupling circuit is driven with an efficient subcutaneous power amplifier and this makes the external impedance increase and reduces the power delivered to the internal circuit. Therefore, the power amplifier should be carefully designed with optimum load resistance $\left(\mathrm{R}_{\mathrm{P}}\right)$ by using a matching network where the lumped elements for the external coil can also be determined [14]. The external impedance including the power amplifier resistance is as illustrated as follows:

$$
\begin{gathered}
Z_{11}=\left[\left(R_{L T}+j \omega L_{T} / / \frac{1}{j \omega C_{S T}}\right)+\frac{1}{j \omega C_{1}}\right]+R_{P} \\
\eta_{T}=\left|\frac{Z_{t}}{Z_{11}+Z_{t}}\right|
\end{gathered}
$$

The PTE equation based on these factors given in the Figure 2 becomes:

$$
\eta_{\text {link }}=\frac{P_{O}}{P_{S}}=\frac{K^{2} Q_{1} Q_{2}^{3} R_{\text {load }} R_{L R}}{\left[K^{2} Q_{1} Q_{2} R_{\text {load }}+\left(1+\frac{R_{P}}{R_{L T}}\right)\left(R_{\text {load }}+Q_{2}^{2} R_{L R}\right)\right] \times\left(R_{\text {load }}+Q_{2}^{2} R_{L R}\right)}
$$

Equations (14) and (17) are modeled in MATLAB based on the values given in the inductive link coil design section (Table 1). The power transfer efficiency for lower input impedance is higher than the efficiency with higher input impedance. 
Table 1. The values and parameters of the external and internal parts.

\begin{tabular}{|c|c|c|c|}
\hline Quantity & Symbol & External Coil & Internal Coil \\
\hline Inductance & $\mathrm{L}$ & $4.92 \mu \mathrm{H}$ & $1 \mu \mathrm{H}$ \\
\hline Series resistance & $\mathrm{R}$ & $2.2 \Omega$ & $1.6 \Omega$ \\
\hline Capacitance & $\mathrm{C}$ & $33.11 \mathrm{pf}$ & $33.11 \mathrm{pf}$ \\
\hline Quality Factor & Q & 190 & 53 \\
\hline Outer diameter & $\mathrm{d}_{\text {out }}$ & $56 \mathrm{~mm}$ & $11.6 \mathrm{~mm}$ \\
\hline Inner diameter & $\mathrm{d}_{\mathrm{in}}$ & $10 \mathrm{~mm}$ & $0.5 \mathrm{~mm}$ \\
\hline Number of turns & $\mathrm{N}$ & 30 & 8 \\
\hline Inductor Width & $\mathrm{w}$ & $0.5 \mathrm{~mm}$ & $0.3 \mathrm{~mm}$ \\
\hline Turn spacing & S & $0.3 \mathrm{~mm}$ & $0.1 \mathrm{~mm}$ \\
\hline Fill factor & $\varphi$ & 0.69 & 0.39 \\
\hline PCB substrate & - & $60 \mathrm{~mm} \times 70 \mathrm{~mm}$ & $12 \mathrm{~mm} \times 15 \mathrm{~mm}$ \\
\hline Link operating frequency & $\mathrm{f}$ & \multicolumn{2}{|c|}{$13.56 \mathrm{MHz}$} \\
\hline Secondary nominal loading & $\mathrm{R}_{\text {load }}$ & \multicolumn{2}{|c|}{$300 \Omega$} \\
\hline Optimum p/Am resistance & $\mathrm{R}_{\mathrm{P}}$ & \multicolumn{2}{|c|}{$41.89 \Omega$} \\
\hline Coupling Coefficients & $\mathrm{K}$ & \multicolumn{2}{|c|}{0.087} \\
\hline Mutual inductance & M & \multicolumn{2}{|c|}{$0.95 \mu \mathrm{H}$} \\
\hline Coil relative distance within tissue & $\mathrm{X}$ & \multicolumn{2}{|c|}{$6 \mathrm{~mm}$} \\
\hline
\end{tabular}

\subsection{Optimization of Maximum Efficiency}

The purpose of the theoretical analysis given above is to facilitate the process of the inductive coupling link optimization. Referring to Figure 2, the optimization is obtained for impedance $Z_{1}$ and $Z_{2}$ by reducing the implanted impedance $Z_{2}$ without considering the power amplifier resistance. The power efficiency takes place at the resonant frequency $\omega_{0}$ on the implanted coil as follows:

$$
\omega_{\text {o.imp }}^{2}=\frac{1}{L_{R} C_{R}}-\left(\frac{1}{C_{R} R_{\text {load }}}\right)^{2}
$$

From Equation (18), it is noted that the resonant frequency depends on $L_{R}, C_{R}$ and $R_{\text {load. }}$. Hence, if there is any change in the implanted load resistance, the coupling system will be out of resonance. Thus, the implanted remote will not receive the maximum transmitted power. The maximum transmitted power between the two coils is achieved when both $L C$ circuits of the external and implanted coil have the same resonance frequency and the imaginary part of the impedance $\mathrm{X}_{\mathrm{eq}}=0$ and this occurs when the load reflected in the transmitter has the same value as the impedance of the transmitter coil in resonance $Z_{1}$ as follows:

$$
P_{\text {max }}=\frac{M^{2}}{L_{R}+\frac{R_{\text {load }}}{R_{\text {load }} C_{R}+1}+R_{L R}}
$$

where $M$ represents the mutual inductance between the external and internal coil, which is calculated in the optimization section. On the secondary side, a resonance capacitor $C_{R}$ cancels the inductive impedance of the receiving coil. The secondary resonance greatly enhances the performance of an inductive link, therefore, this capacitor playing a big rule in the efficiency enhancement. Referring to 
Equation (19), the optimization can be achieved by adjusting the capacitor $C_{R}$ to get optimum resonance as given in Equation (20):

$$
C_{R}=\frac{R_{L} \pm \sqrt{R_{L}^{2}-4 L_{R}^{2} \omega_{0}^{2}}}{2 L_{R} R_{\text {load }} \omega_{o}^{2}}
$$

Hence, we optimize the power transmission efficiency of the inductive link, which is given in Equation (14), without considering the power amplifier resistance that can be expressed as given in Equation (21):

$$
\begin{gathered}
\eta_{\text {opt }}=\frac{\left|I_{2}\right|^{2} R_{\text {load }}}{R_{\text {eq }}\left[I_{1}\right] V_{s}} \\
R_{\text {eq }}=\frac{R_{L R} R_{\text {load }}\left(R_{\text {load }}+R_{L R}\right)+2 \omega^{2} L_{\text {imp }} R_{\text {load }}}{\left(R_{\text {load }}-\omega^{2} L_{\text {imp }} C_{R} R_{L r}+R_{L r}\right)^{2}+\left(2 \omega L_{\text {imp }}+\omega C_{R} R_{\text {Lr }} R_{\text {load }}\right)^{2}}
\end{gathered}
$$

where $R_{\text {eq }}$ presents the real part of the implant coil impedance and $L_{\text {imp }}$ represents the implanted coil that involves lumped elements $\left(\mathrm{L}_{\mathrm{R}}, \mathrm{R}_{\mathrm{LR}}, \mathrm{C}_{\mathrm{SR}}\right)$.

\section{Coils Design and Optimization}

In general, the coil design and optimization can be achieved based on two methods-coupling based and coil geometry based. The optimization based on coupling is used to optimize the power transfer efficiency, data rate transmission, voltage gain and bandwidth. The optimization based on coil geometry is used to enhance the coil performance in air and within the tissue. In this section, the methodology to design the inductive link based on spiral circular coil geometry is introduced. This optimization can be achieved by developing rules and formulas presented in previous studies. The optimization is obtained based on the coil geometry parameters such as coil shape, outer and inner dimensions, mutual inductance $(\mathrm{M})$, self-inductance $(\mathrm{L})$, coefficient factor $(\mathrm{K})$ and fill factor $(\varphi)$.

\subsection{Spiral Coil Characterization}

The HFSS software is used to validate and simulate the proposed printed spiral circular coils and design the tissue model. In order to reduce the power losses in the transmission load, 1-0Z copper wire (30 AWG) with $0.036 \mathrm{~mm}$ thickness is printed on Rogers $4350^{\mathrm{TM}}$ substrate with constitutive parameters of $1.5 \mathrm{~mm}$ substrate thickness, 4.4 (FR4) dielectric constant, 3.66 relative permittivity $\left(\varepsilon_{\mathrm{r}}\right)$, 0.004 dielectric loss tangent and " 1 " relative permeability $\left(\mu_{\mathrm{r}}\right)$, respectively. The implanted coil is coated by RH-5 substrate with $\varepsilon_{\mathrm{r}}=1.0006$ and loss tangent $=0$. The external coil is printed on a substrate having dimensions of $70 \times 60 \times 1.5 \mathrm{~mm}$ while the internal coil is printed on a substrate having dimensions of $12 \times 15 \times 1.5 \mathrm{~mm}$ as shown in Figure 3. The calculated parameters of the transmitter and receiver coils will be explained in detail in the coil design section and as given in Table 1. 
Figure 3. Coil geometries simulated by HFSS software.

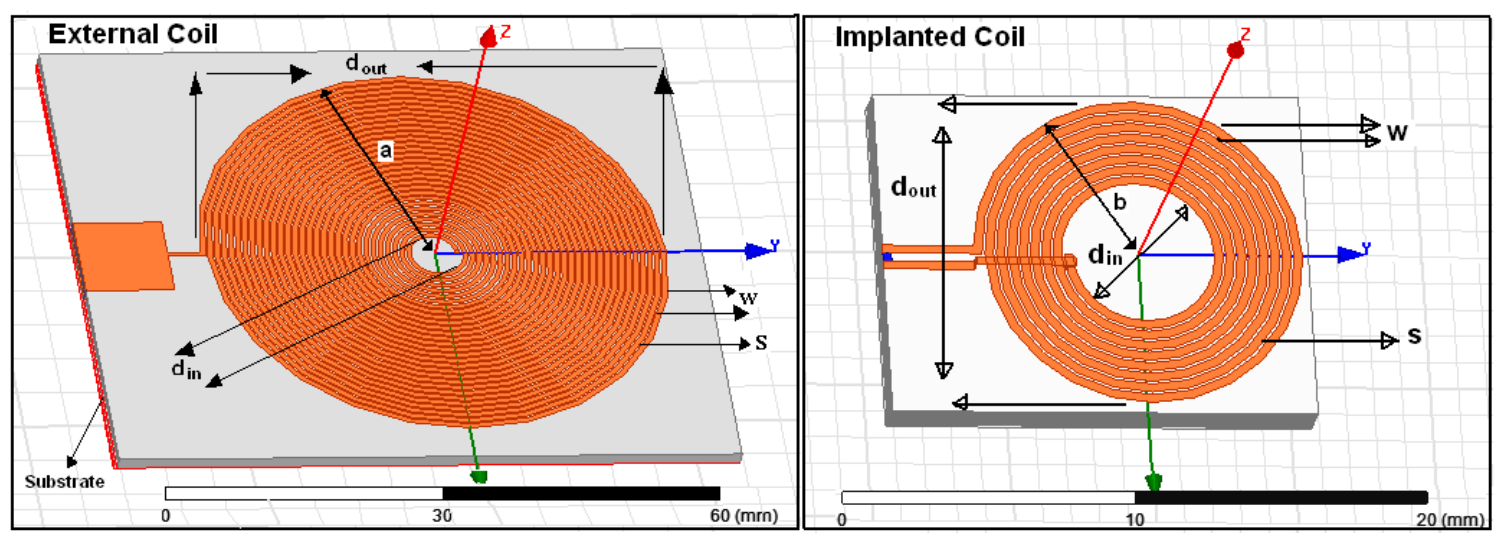

\subsection{Optimization of Geometric Design Based on Circular Spiral Coils}

Circular spiral coils are widely used in implanted devices as inductive coupling links due to their robustness against lateral coil misalignment. Because the external coil is fixed outside the body, it can be improved by increasing the dimensions of the coil. The design of the internal coil is limited by many factors such as shape, weight, number of turns and size, hence, the outer dimension of the implanted coil should be small, with a few turns, and should have a low consumption to prevent tissue heating. The proposed coils are used for the implanted microsystem in the radiating near-field (Fresnel) region at an operating frequency of $13.56 \mathrm{MHz}$ in the arrow-band. The EM fields around the coils should be constant and confirm the omnidirectional pattern associated with such loop antennas, which allows better links with the implanted coil. In the case of circular loops, the distance of the radiation (D) is defined by the outer transmitted coil dimensions $\left(d_{\text {out }}\right)$ and should satisfy the condition adopted by Finkenzeller [15] as given in Equation (23):

$$
d_{\text {out }} \leq D 2 \sqrt{2}
$$

The mutual distance between the transmitter and receiver circular coils should satisfy the expression Equation (24) [16] which we modified as given in Equation (25):

$$
a=\sqrt{X^{2}+b^{2}}
$$

where $\mathrm{a}$ and $\mathrm{b}$ represents the external and implanted coils radius, respectively:

$$
\frac{d_{\text {out } . T}}{2}=\sqrt{X^{2}+\left(\frac{d_{\text {out } . R}}{2}\right)^{2}}
$$

where $X$ represents the mutual distance between coils and $d_{\text {out.T }}, d_{\text {out.R }}$ presents the external and internal outer dimensions for the transmitter and receiver coil as shown in Figure 3.

The methods used in calculating the mutual inductance between the two coils and the self-inductance of such coils have been previously reported $[17,18]$ and for the spiral circular coils they are adapted from [19]. The mutual inductance of two parallel filament coils $(\Delta=0)$ and separated by $\mathrm{X}$ distance and having a $\mathrm{d}_{\mathrm{T}}$ and $\mathrm{d}_{\mathrm{R}}$ of dimensions can be expressed as follows: 


$$
M\left(d_{T}, d_{R}, \Delta=0, X\right)=\frac{1}{2} \mu_{0} \sqrt{d_{T} \times d_{R}}\left[\left(\frac{2}{f}-f\right) K(f)-\frac{2}{f} E(f)\right]
$$

where $\mu_{0}=4 \pi \times 10^{-9} \mathrm{H} / \mathrm{cm}$ and represent the permeability of space, $K(f), E(f)$ represents the elliptic integrals given in Equation (27):

$$
f\left(d_{T}, d_{R}, \Delta=0, X\right)=\sqrt{\frac{4 d_{T} d_{R}}{\left(d_{T}+d_{R}\right)^{2}+X^{2}}}
$$

The summations of the partial mutual inductance for both coils need a complex analytical model. Hence, circular coils having a simple mathematical model are proposed, and the external and internal coils have a very small space between each turn as given in Table 1. Therefore, Lyle's method [20] is used for the considered external and internal coils having two circular filaments with dimensions $d_{\text {out.T }}$, $d_{\text {in.T }}$ and $d_{\text {out.R }}, d_{\text {in.R }}$, respectively, and having an arithmetic geometric average as given in Equation (28):

$$
d_{\text {avg }}=0.5 \times\left(d_{\text {out }}+d_{\text {in }}\right)
$$

where $d_{\text {out }}$ and $d_{\text {in }}$ represent the outer and inner coil dimensions. Hence, the approximated mutual inductance between two spiral circular coils is found as a function of the number of turns for each coil, coil dimensions and distance, which can be developed and simplified as given in Equation (29) [15,21]:

$$
M \cong \frac{\mu_{0} N_{T} d_{\text {out.T }}^{2} N_{R} d_{\text {out. } R}^{2} \pi}{2 \sqrt{\left(d_{\text {out } . R}^{2}+X^{2}\right)^{3}}}
$$

where $N_{T}$ and $N_{R}$ are the number of turns of the transmitter and receiver coils.

The self-inductance such as that of the spiral circular planar coil is determined based on the approximation of the spirals and equivalent current densities and be calculated as given in Equation (30):

$$
L=\frac{C_{1} \mu_{0} N^{2} d_{\text {avg }}}{2}\left[l_{n}\left(\frac{C_{2}}{\varphi}\right)+C_{3} \varphi+C_{4} \varphi^{2}\right]
$$

where $\mathrm{N}$ represents the numbers of turns for such circular coil, $\mathrm{C}_{\mathrm{i}}$ is a dependent coefficient, In this case it is a circle for which the coefficients are $C_{1}=1.00, C_{2}=2.46, C_{3}=0.00, C_{4}=0.20$ [18]. The arithmetic geometrical averages like the fill ratio defined as $\varphi$ have to be computed and calculated as illustrated in Equation (31):

$$
\varphi=\frac{\left(d_{\text {out }}-d_{\text {in }}\right)}{\left(d_{\text {out }}+d_{\text {in }}\right)}
$$

To design and optimize our spiral circular coil (pancake) we used two concepts; the first one is based on Equation (24), where the external coils' radius is approximately equal to the distance to be covered (for a small internal coil). On the other hand, the mutual distance between the external and implanted coils is about twice the implanted coil diameter. The second one is based on the relations between the outer and internal coils. Then increasing mutual distance can be solved by optimizing the coil dimensions by making $\mathrm{d}_{\text {in. } \mathrm{T}} \approx 0.18 \mathrm{~d}_{\text {out. } \mathrm{T}}$ and $\mathrm{d}_{\text {in. } \mathrm{R}} \approx 0.75 \mathrm{~d}_{\text {out.R }}$ respectively, [19]. Using the equation approximations above and the chart from Figure 4, the external coil outer dimensions are assumed $\mathrm{d}_{\text {out. } \mathrm{T}}=56 \mathrm{~mm}$ then $\mathrm{d}_{\text {in. } \mathrm{T}}=10 \mathrm{~mm}$, the implanted coil dimensions found $\mathrm{d}_{\text {out.R }}=11.6 \mathrm{~mm}$, and $\mathrm{d}_{\text {in. } \mathrm{R}}=5 \mathrm{~mm}$, respectively [22]. To validate our design optimization, the values above were inserted 
into Equation (25), giving as mutual distance result $X=22 \mathrm{~mm}$ which is much closer to the radiated distance from the external coil given in Equation (23) where $\mathrm{D}=20 \mathrm{~mm}$. The coefficient factor $(K)$ is calculated based on coils' dimensions. Since its for an implanted microsystem usually $\mathrm{d}_{\text {out.T }} \geq \mathrm{d}_{\text {out.R }}$ and according to the values given in Table 1. In our applications we used a tissue thickness of $6 \mathrm{~mm}$ as a mutual distance between the coils, hence, the coefficient coupling $(K)$ is calculated as follows:

$$
K=\frac{a^{2} x b^{2}}{\sqrt{a b}\left(\sqrt{a^{2}+X^{2}}\right)^{3}}
$$

To validate the parameters $M$ and $K$, Equations (29) and (32) were modulated in MATLAB as shown in Figure 4a,b, respectively.

Figure 4. the relationship between (a) Coupling coefficient; (b) mutual inductance and distance between two coils.

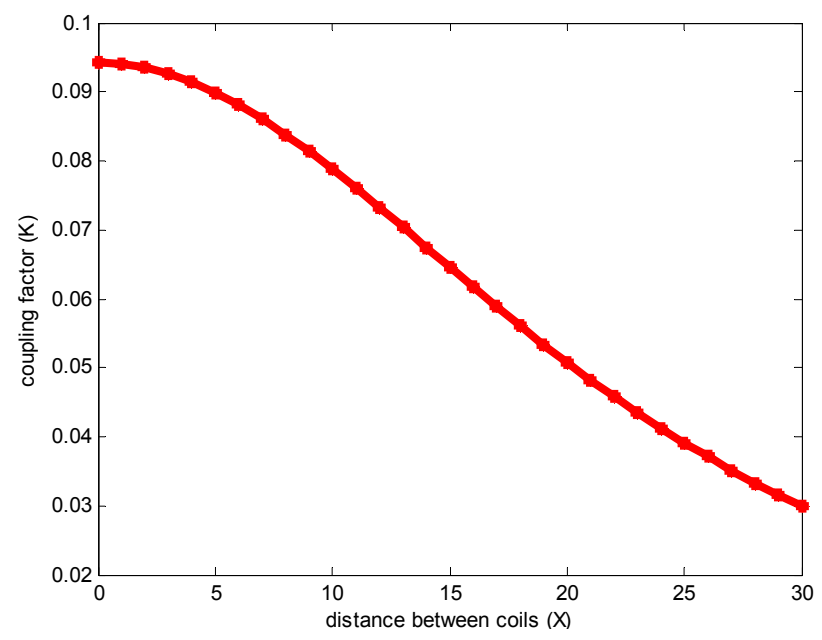

(a)

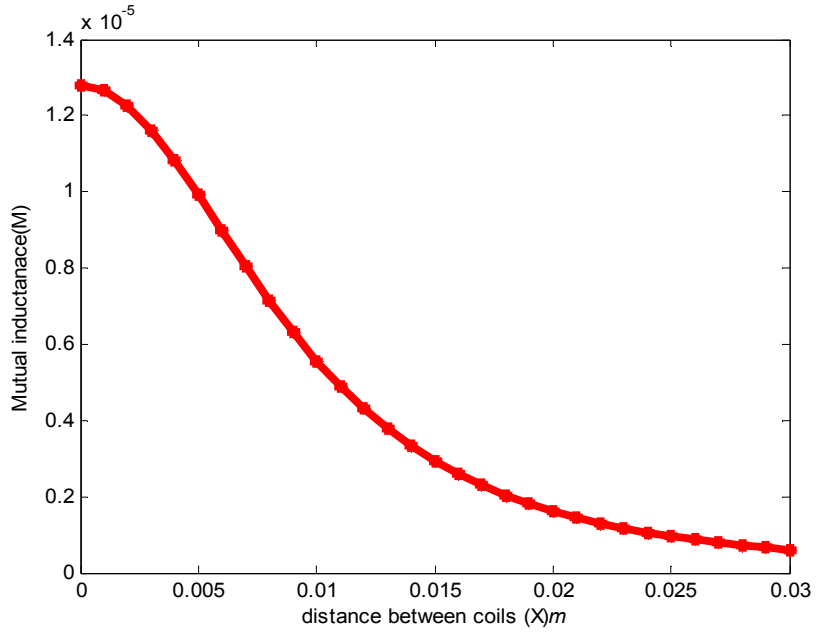

(b)

For information and clarification, the dielectric constitutive parameters of the biological human tissue at low band frequencies such as $13.56 \mathrm{MHz}$ are not available in the specialized scientific research and literature; approximate body tissue dielectric data are available in [23].

\section{Human Biological Tissue and SAR at $13.56 \mathrm{MHz}$}

The implanted coil receives the energy transferred by external coils through the human tissue. Therefore, the human tissue must be taken into account. Because it is not allowed to use the living human tissue in testing, and cadavers are not suitable for testing because they lose the tissue properties $10 \mathrm{~h}$ after death, and their temperature becomes lower than $22^{\circ}$. In addition, the use of the animal tissue (e.g., ground beef, pig tissue and mouse tissue) does not give the real desired results because of the totally different constitutive parameters between the human and the animal tissue. As a solution, we designed the biological human tissue model with its constitutive parameters in HFSS and used it as a medium separating the two parts.

The conductivity, permeability and the loss-tangent of the human tissue are considered in our proposed design, while other designers did not consider such constitutive parameters of all types of the tissue layers in their designs or they only considered air as the main medium $[9,24,25]$. They claimed 
that the frequencies below $20 \mathrm{MHz}$ couldn't damage the tissue, so most designers haven't considered the tissue when the operating frequency is lower than $20 \mathrm{MHz}$ or they used only one type of tissue.

Therefore, in this work, two types of biological human tissue with wet and dry skin are proposed as the medium separating the coils. The external coil contacts the skin, and the internal coil is implanted within the tissue at a depth of $6 \mathrm{~mm}$. Hence, the magnetic flux links the implanted coil and the external coil and transfers power to the implanted coil. Each type of proposed human biological tissue consists of three layers, the first layer is the skin with $1 \mathrm{~mm}$ thickness, the second layer is the fat with $2 \mathrm{~mm}$ thickness and the third layer is muscle with $3 \mathrm{~mm}$ thickness. The total tissue dimension is $70 \mathrm{~mm} \times 60 \mathrm{~mm} \times 6 \mathrm{~mm}$ and it is designed using HFSS as shown in Figure 5. In this process, the EMF is solved at $13.56 \mathrm{MHz}$.

Figure 5. Pancake coils simulated with a proposed dimension of a human biological tissue model.

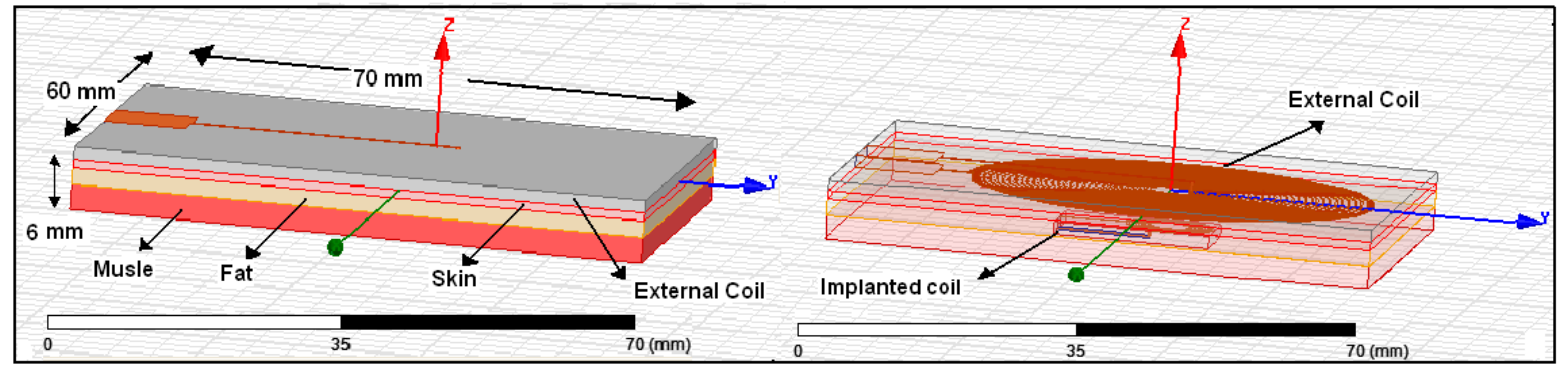

The implanted and external coils surrounding gain was defined on a sphere of radius $12 \mathrm{~cm}$ and $28 \mathrm{~cm}$, respectively, which defines the region around the antenna. Our chosen frequency is $13.56 \mathrm{MHz}$ and is compared with the International Commission on Non-Ionizing Radiation Protection (ICNIRP) and Federal Communications Commission (FCC) standards. Both standards require that the SAR level be at or below $1.6 \mathrm{Wkg}^{-1}$ spread over a volume of $1 \mathrm{~g}$ of tissue, whereas the SAR limit is $2 \mathrm{Wkg}^{-1}$ averaged over $10 \mathrm{~g}$ of tissue [25]. At frequencies lower than $20 \mathrm{MHz}$, the SAR is very small compared with the SAR standard. Therefore, to validate that the proposed internal coil cannot damage the tissue due to electromagnetic absorption, the high accuracy field solver SEMCAD 14.6 was used to calculate the SAR using numerical techniques with a finite-difference time domain (FDTD).

\section{SAR and Power Losses Calculation inside the Tissue}

In order to estimate the power losses inside the human body, numerical calculation methods can be used. In general, determining SAR can be achieved by using numerical techniques or experimental methods by using fabricated tissue phantoms, where the given results are not close to reality, in addition the power losses cannot be determined within tissue [26]. Other studies have tried to fabricate gels exhibiting similar electrical properties as tissues for testing implantable devices and these gels are used to examine the interaction between electromagnetic waves and biological tissues. All this gel was fabricated according to the Industrial, Scientific and Medical (ISM) 2.4-2.48 GHz band, and according to the medical implant communications service (MICS) 402-405 $\mathrm{MHz}$ one [27]. The gels are fabricated by making an artificial material which shows electrical features approximately similar to human skin tissue. The contents of this material are oil, sugar, Triton, agarose, $\mathrm{NaCl}$ and deionized water). This fabricated gel suffered from several problems such as quick loss water as a result of the 
evaporation process and it cannot keep a fixed temperature like the temperature of the human body. Thus it loses its properties quickly, and hence it must be kept in designated places. For our work, we didn't find any studies that fabricated gels for low band frequency (1-20 MHz). In addition, we believe that whatever the accuracy of the tissue phantom manufacturer, it cannot be absolutely similar to the living human tissue.

As a solution, we used such specific and accurate software (SIMCAD) with a high resolution 3-D human body model, and we selected the position of the implanted coil and the tissue with its real constitutive parameters at $13.56 \mathrm{MHz}$ [28]. Then, to calculate SAR and power losses within tissue, the implanted coil was designed using Pspice, which it is compatible with the SEMCAD software, and powered it with five voltages and $150 \mathrm{~mW}$. Then the proposed implanted coil was inserted into the 3D model at the top of the adult human head in the space between the skull and brain at a depth of less than $1 \mathrm{~cm}$. The SEMCAD software provides a high level of anatomical details and avoids using practical experiments on live human tissue. These models play an important role in optimizing the evaluation of electromagnetic exposures, e.g., in human body models [29]. A future task of this study will be to fabricate phantom tissues having constitutive parameters at $13.56 \mathrm{MHz}$ according to [29] but this fabrication may only be done by certain companies.

\section{Results and Discussion}

In this study, a theoretical analysis of PS topology inductive coupling links is presented. The mathematical analysis is modeled in MATLAB using the reflected impedance method to determine the power transmission efficiency between the two parts. The reflected impedance concept analysis is optimized and modified to obtain efficient power transmission between the two pairs of proposed single-layer planar spiral circular coils, which are printed on small PCBs made of substrate. In the reflected impedance method, two approaches were used; the first approach is the analysis done without considering the power amplifier resistance, and the second approach is with power amplifier resistance. The implanted load resistor is considered $200 \Omega$ to $400 \Omega$, and for implanted microsystem purposes, the needed distance between coils is $6 \mathrm{~mm}$ with a coefficient factor of 0.087 and mutual inductance of $0.95 \mu \mathrm{H}$.

Figure $6 a, b$ shows the variation of power efficiency with various resistances and coefficient factors with high and low input impedance, respectively. The maximum efficiency without power amplifier resistor is $80 \%$, and the worst efficiency is $73 \%$, whereas, the maximum efficiency with the power amplifier consideration is $45 \%$ and the worst efficiency is $32 \%$. The results showed that the power efficiency with power amplifier resistance (high input impedance) is approximately 55\% more than that without power amplifier resistance (low input impedance).

To test the proposed coils' performance, and to find the natural fields surrounding the coil in air and in human biological tissue, the model is analyzed and optimized using the commercial field solver HFSS 13.0. The coils were investigated in two conditions; the first condition was when air (free space) separated the coils placed at distances of $6 \mathrm{~mm}$. The second condition was when simulated human biological tissue with dry and wet skin replaced the air. 
Figure 6. Power efficiency links (a) with low and high impedance; (b) with low input impedance and various load resistances.

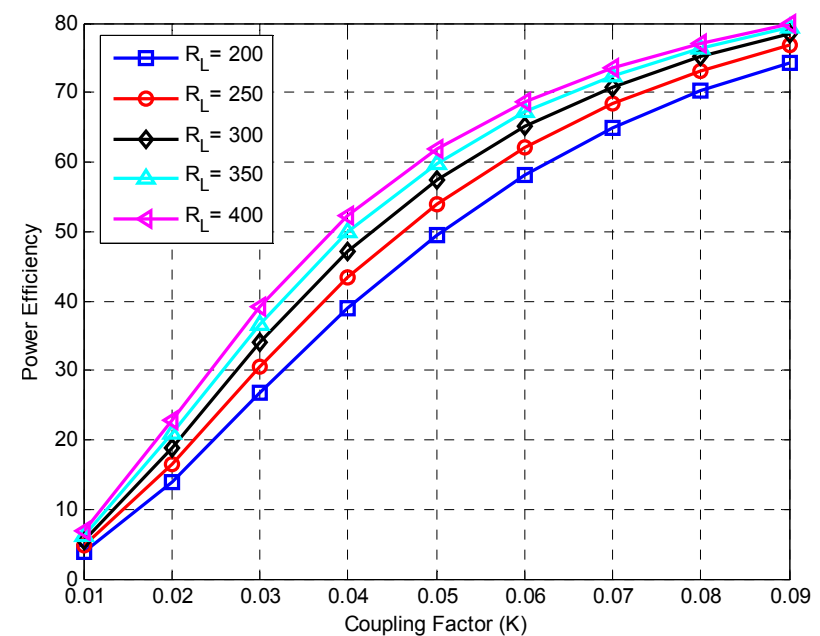

(a)

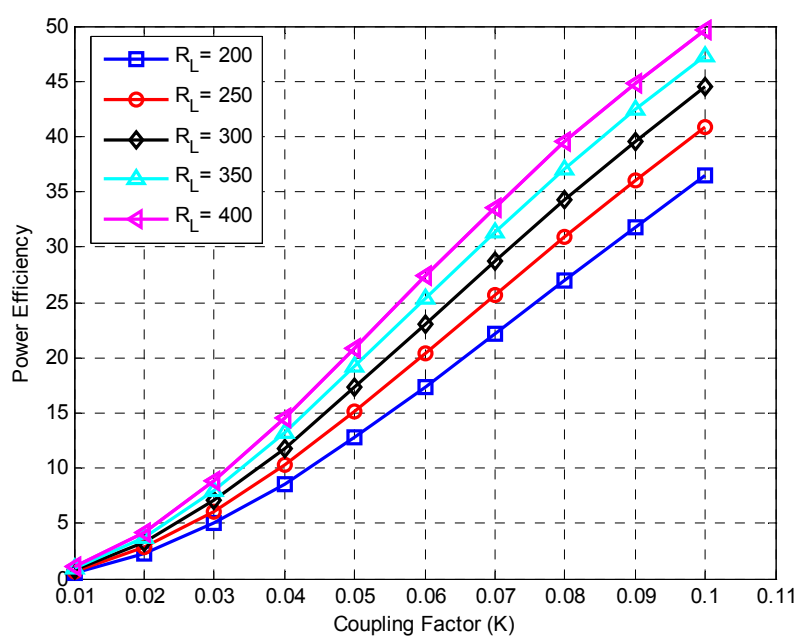

(b)

\subsection{Near-Fields Surrounding Coils on Air}

The combined magnitude of the electric field components (elevation and azimuthal planes) for external and internal coils in air can be explained as follows: Figure 7 illustrates the simulated natural E-Total near-field patterns surrounding external coil on air at a distance of $6 \mathrm{~mm}$, where Figure $7 \mathrm{a}$ shows that the total near field on the azimuthal plane $\left(\theta=0^{\circ}, \theta=90^{\circ}\right)$ are approximately $-36 \mathrm{~dB}$ and $-3 \mathrm{~dB}$, respectively, and the surrounding fields are omnidirectional at all angles. Figure $7 \mathrm{~b}$ shows that the surrounding fields on the elevation plane $\left(\Phi=0^{\circ}, \Phi=90^{\circ}\right)$ are approximately $-3 \mathrm{~dB}$ and $-28 \mathrm{~dB}$. The magnitude of the electric field surrounding the coil is omnidirectional and there is a drop and change in the magnitude in some specific angles.

Figure 7. Simulated patterns for total near field surrounding external coil on air: (a) on the azimuthal plane $\left(\theta=0^{\circ}, \theta=90^{\circ}\right)$; (b) on the elevation plane $\left(\Phi=0^{\circ}, \Phi=90^{\circ}\right)$, respectively.

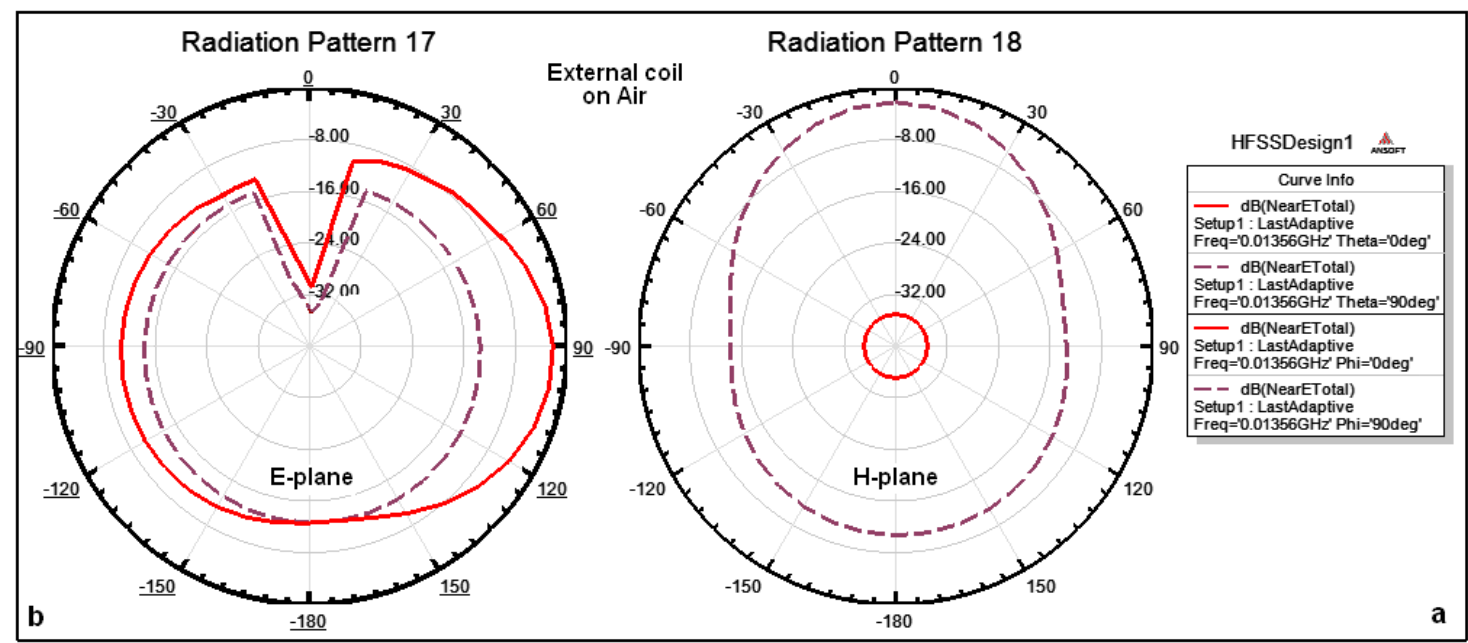


The outer dimensions of the implanted coil are smaller than those of the external coil; therefore the gain surrounding the implanted coil is lower than the gain surrounding the external coil. Figure 8 illustrates the simulated natural fields surrounding the internal coils in air at $6 \mathrm{~mm}$ distance where Figure $8 \mathrm{a}$ shows that the total near fields on the azimuthal plane $\left(\theta=0^{\circ}, \theta=90^{\circ}\right)$ are approximately $-68 \mathrm{~dB}$ and $-18 \mathrm{~dB}$, respectively, and the magnitude of the electric field surrounding the coil is omnidirectional at all angles. Figure $8 \mathrm{~b}$ shows that the total near fields on the elevation plane for both $\Phi=0^{\circ}, \Phi=90^{\circ}$ are approximately $-22 \mathrm{~dB}$. The magnitude of the electric field surrounding the coil is omnidirectional and there is a drop in the magnitude at some specific angles of up to $-48 \mathrm{~dB}$.

Figure 8. Simulated patterns for total near field surrounding an internal coil on air: (a) on the azimuthal plane $\left(\theta=0^{\circ}, \theta=90^{\circ}\right)$; (b) on the elevation plane $\left(\Phi=0^{\circ}, \Phi=90^{\circ}\right)$, respectively.

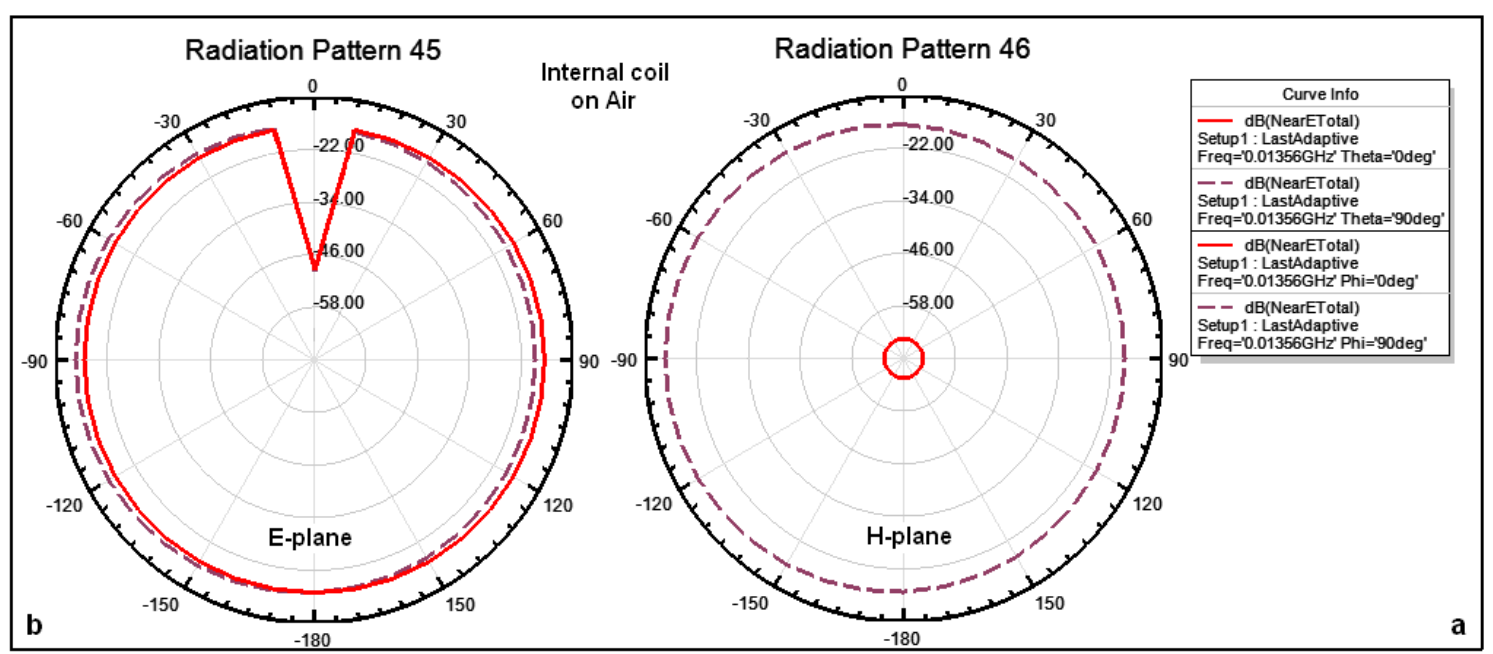

\subsection{Near-Fields Surrounding Coils within Tissue}

The external coil contacts the skin and the internal coil is implanted inside the tissue at a depth of $6 \mathrm{~mm}$. Therefore, the combined magnitude of the electric field components for external and internal coils within tissue can be explained as follows: Figure 9 illustrates the simulation of the near-field patterns E-Total surrounding the external coil on the azimuthal plane $\left(\theta=0^{\circ}, \theta=90^{\circ}\right)$, and on the elevation plane $\left(\Phi=0^{\circ}, \Phi=90^{\circ}\right)$. Because the external coil just contacts the tissue therefore, there is no tissue effect on the coil performance and the amount of the surrounding coil is similar to the results given in Figure 7.

The internal coil is implanted in the tissue at a depth of $6 \mathrm{~mm}$, hence the coil performance is different from the coil performance when it is in free space. Figure 10 illustrates the simulated natural fields surrounding the internal coils within tissue at a depth of $6 \mathrm{~mm}$. Figure 10a shows that the total near fields on the azimuthal plane $\left(\theta=0^{\circ}, \theta=90^{\circ}\right)$ are approximately $-88 \mathrm{~dB}$ and $-38 \mathrm{~dB}$, respectively, and the magnitude of the electric field surrounding the coil is omnidirectional at all angles except for some specific angles. Figure 10b shows that the total near fields on the elevation plane for both $\left(\Phi=0^{\circ}, \Phi=90^{\circ}\right)$ are approximately $-38 \mathrm{~dB}$. The magnitude of the electric field surrounding the coil is omnidirectional and there is a drop in the magnitude for some specific angles of up to $-68 \mathrm{~dB}$. 
Figure 9. Simulated patterns for total near field surrounding external coil when it contacts the tissue: (a) On the azimuthal plane $\left(\theta=0^{\circ}, \theta=90^{\circ}\right)$; (b) on the elevation plane $\left(\Phi=0^{\circ}\right.$, $\Phi=90^{\circ}$ ), respectively.

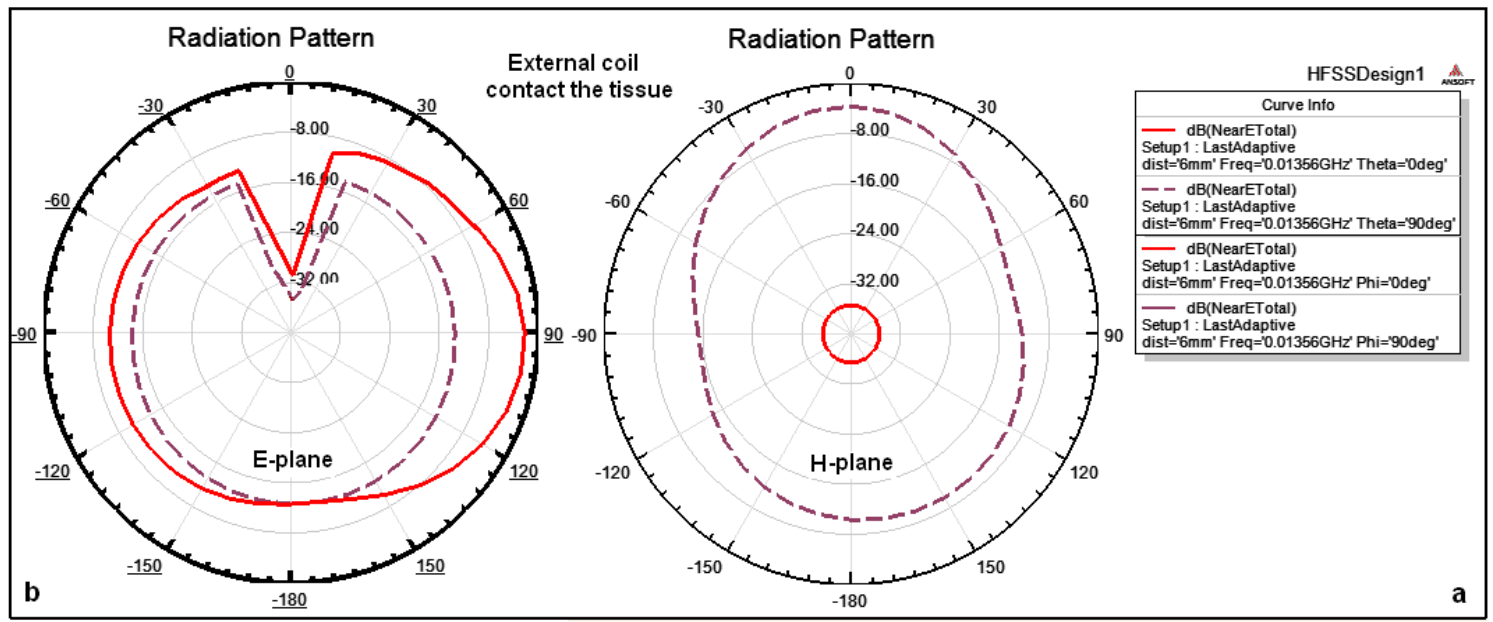

Figure 10. Simulated patterns for total near field surrounding an internal coil within tissue: (a) on the azimuthal plane $\left(\theta=0^{\circ}, \theta=90^{\circ}\right)$; (b) on the elevation plane $\left(\Phi=0^{\circ}\right.$, $\left.\Phi=90^{\circ}\right)$, respectively.

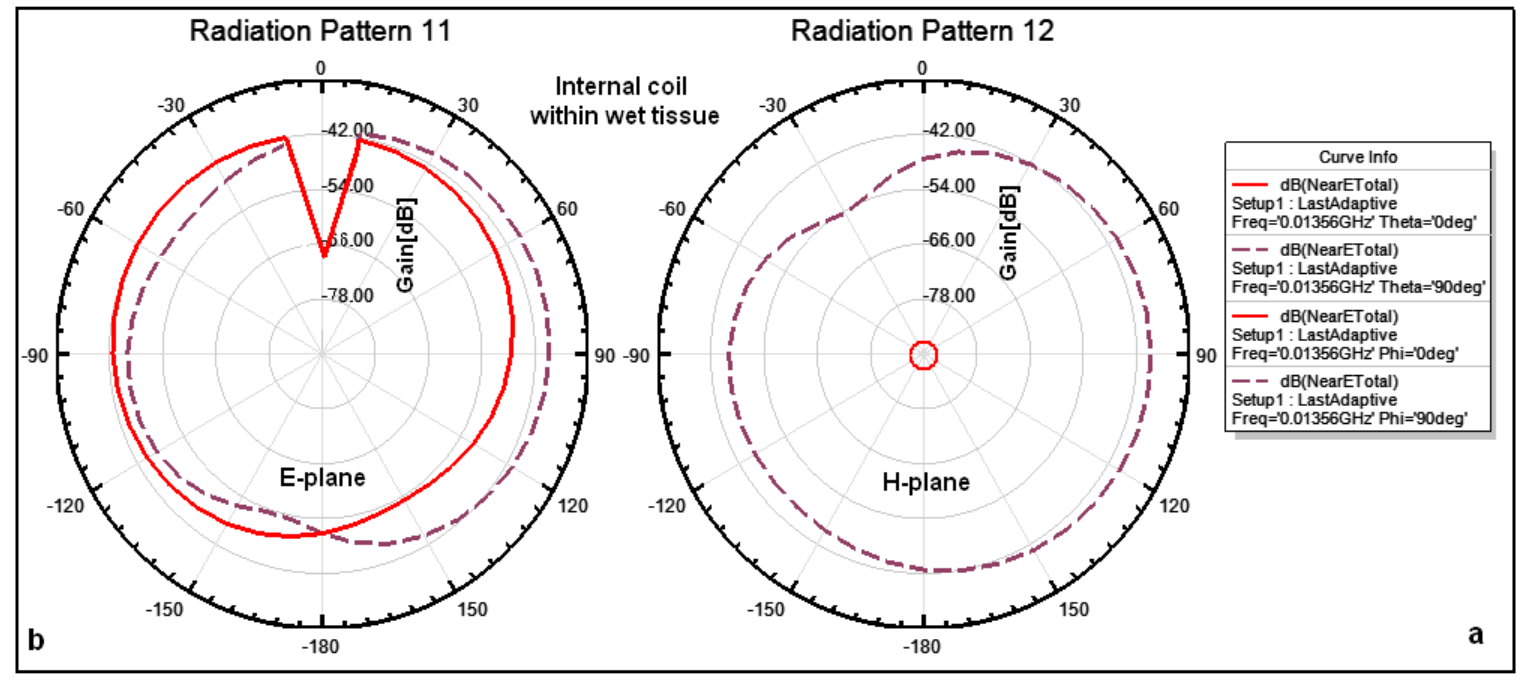

\subsection{Specific Absorption Rate (SAR) Effects and Power Loss}

One of the important situations of transferring signals via inductive coupling is when the tissue is facing an electromagnetic field. Such a tissue will derive the power to be dissipated inside the tissue itself, therefore the temperature will be increased around the tissue. As a result, the tissues that surround the coil may be damaged. However, power dissipation and SAR should be within the accepted range. In our design, the coils are separated by biological tissue. Thus, the SAR and power losses of the proposed coils operating at $13.56 \mathrm{MHz}$ would not be damaging to the tissue. To prove that, the implanted coil was inserted at the top of the head in the space between the skull and brain at a depth of less than $1 \mathrm{~cm}$. Figure 11 shows the SAR level and the power loss within the tissue where the SAR is equal $7.09 \times \mathrm{e}^{-021} \mathrm{~mW} / \mathrm{g}$, and the power loss is $1.402 \times \mathrm{e}^{-025} \mathrm{~W}$. The results above show that 
the SAR was much less than the standard for $1 \mathrm{~g}$ and is negligible for $10 \mathrm{~g}$. The power loss effect is negligible. Both results showed that the proposed implanted coil has a negligible SAR and a power loss effect.

Figure 11. The SAR and power loss in the human body at $13.56 \mathrm{MHz}$ frequency, at a depth of $10 \mathrm{~mm}$.

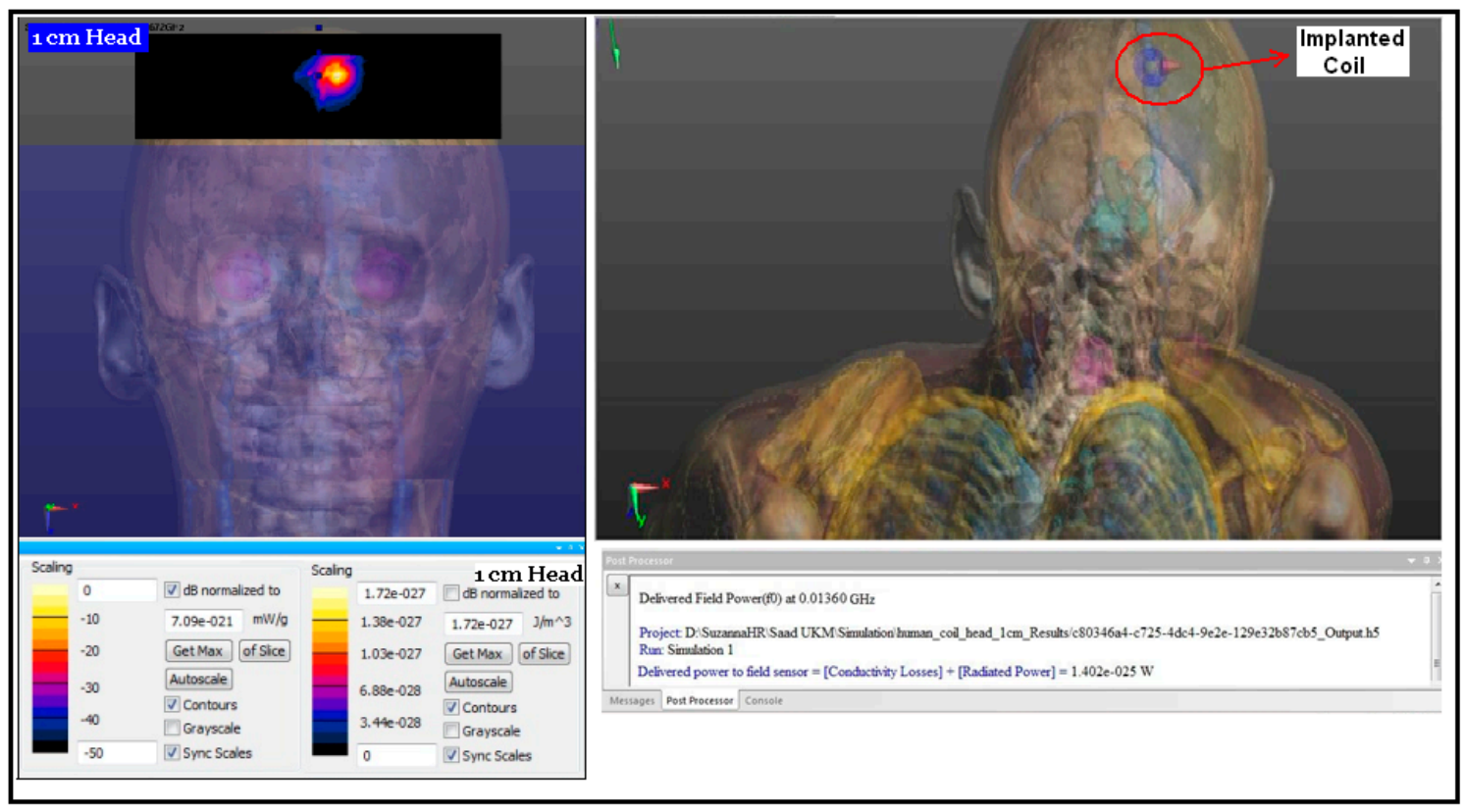

\section{Conclusions}

In this study, a theoretical analysis for an inductive coupling link is optimized by using the reflected impedance method to achieve a power transmission efficiency of up to $80 \%$. The inductive link based on a spiral circular (pancake) design was developed and tested in air and in two types of the biological human tissue (dry and wet skin) having a thickness of $6 \mathrm{~mm}$, at a frequency of $13.56 \mathrm{MHz}$. The designed coils can be used for implanted micrssystem applications, where the maximum depth is $6 \mathrm{~mm}$ as given in the literature review. The coil values and geometries are given in Table 1. The results showed that the maximum gain surrounding the external coil in the air and on tissue is $-3 \mathrm{~dB}$ and it is almost constant and has an omnidirectional pattern, therefore, the external coil performance in tissue is approximately $98 \%$ than it air. The internal coil performance within tissue is approximately $50 \%$ that in air. The SAR is extremely small and lower than the standard level, thus, the tissue is not heated and cannot be damaged, and power loss within the tissue is very small and can be ignored. The implant coil dimensions are small and it performed well, making it highly suitable for implanted microsystem applications.

\section{Acknowledgement}

This work supported by the Universiti Kebangsaan Malaysia under Grant UKM-DIP-2012-03. 


\section{Author Contributions}

Saad Mutashar: Collected, organized, modified, optimized, revised, prepared the manuscript, read and approved the final manuscript. Mahammad A. Hannan: Modified, edited, revised, read and approved the final manuscript. Salina A. Samad and Aini Hussain: Both authors edited, revised, read and approved the final manuscript.

\section{Conflicts of Interest}

The authors declare no conflict of interest.

\section{References}

1. Hannan, M.; Saad, M.; Salina, A.S.; Aini, H. Modulation techniques for biomedical implanted devices and their challenges. Sensors 2012, 12, 297-319.

2. Harrison, R.R.; Watkins, P.T.; Kier, R.J.; Lovejoy, RO.; Black, D.J.; Greger, B.; Solzbacher, F. A low-power integrated circuit for a wireless 100 -electrode neural recording system. IEEE $J$. Solid-State Circuits 2007, 42, 123-133.

3. Humayun, M.S.; Weiland, J.D.; Fujii, G.Y.; Greenberg, R.; Williamson, R.; Little, J.; Mech, B.; Cimmarusti, V.; Boemel, G.V.; Dagnelie, G.; et al. Visual perception in a blind subject with a chronic microelectronic retinal prosthesis. Vis. Res. 2003, 43, 2573-2581.

4. Clark, G.M. Cochlear Implants: Fundamentals and Applications; Springer-Verlag: New York, NY, USA, 2003.

5. Reinhold, C.; Scholz, P.; John, W.; Hilleringmann, U. Efficient antenna design of inductive coupled RFID-systems with high power demand. IEEE J. Commun. 2007, 2, 14-23.

6. Haidar, M.R.; Islam, S.K.; Zhang, M.; Tacho, O. Low-power low-voltage current readout circuit for inductively powered implant system. IEEE Trans. Biomed. Circuits Syst. I 2010, 4, 205-213.

7. Mutashar, S.A.; Hannan, M.A.; Salina, A.S.; Hussain A. Development of Bio-Implanted Micro-System with Self Recovery ASK Demodulator for Transcutaneous Applications. J. Mech. Med. Biol. 2014, 14, 1450062.

8. Luis, A.; Rui, F.X.; Kuang, W.C.; Minkyu, J. Closed loop wireless power transmission for implantable medical devices. In Proceedings of the IEEE 13th International Conference on Integrated Circuits (ISIC), Singapore, 12-14 December 2011; pp. 404-407.

9. Meysam, Z.; Glenn, P. Maximum achievable efficiency in near-field coupled power-transfer systems. IEEE Trans. Biomed. Circuits Syst. 2012, 6, 228-245.

10. Li, X.; Zhang, H.; Peng, F.; Li, Y.; Yang, T.; Wang, B.; Fang, D. A wireless magnetic resonance energy transfer system for micro implantable medical sensors. Sensors 2012, 12, 10292-10308.

11. Sauer, C.; Stanacevic, M.; Cauwenberghs, G.; Thakor, N. Power harvesting and telemetry in CMOS for implanted devices. IEEE Trans. Circuits Syst. I Reg. Pap. 2005, 52, 2605-2613.

12. Zierhofer, C.; Hochmair, E. High-efficiency coupling-insensitive transcutaneous power and data transmission via an inductive link. IEEE Trans. Biomed. Eng. 2002, 37, 716-722. 
13. Ghazi, B.H.; Hamadi, G.; Mounir, S. Design of Wireless Power and Data Transmission Circuits for Implantable Bio-Micro System. Biotechnol. J. 2007, 6, 153-164.

14. Mutashar, S.A.; Hannan, M.A.; Salina, A.S. Efficient Class-E Design for Inductive Powering Wireless Biotelemetry Applications. In Proceedings of the IEEE International Conference on Biomedical Engineering (ICoBE), Penang, Malaysia, 27-28 February 2012; pp. 445-449.

15. Finkenzeller, K. RFID Handbook: Fundamentals and Applications in Contactless Smart Cards and Identification, 2nd ed.; Wiley: New York, NY, USA, 2003.

16. Ko, W.H.; Liang, S.P.; Fung, C.D. Design of radio-frequency powered coil for implanted instruments. J. Med. Biol. Eng. Comput. 1977, 15, 634-640.

17. Soma, M.; Galbraith, D.C.; White, R.L. Radio-frequency coils in implantable devices: Misalignment analysis and design procedure. IEEE Trans. Biomed. Eng. 1987, 34, 276-282.

18. Mohan, S.S.; Hershenson, M.; Boyd, S.P.; Lee, T.H. Simple Accurate Expressions for Planar Spiral Inductances. IEEE J. Solid-State Circuits 1999, 34, 1419-1424.

19. Harrison, R. Designing efficient inductive power links for implantable devices. In Proceedings of the IEEE International Symposium on Circuits and Systems (ISCAS), New Orleans, LA, USA, 27-30 May 2007; pp. 2080-2083.

20. Grover, F.W. Inductance Calculations: Working Formulas and Tables; D. Van Nostrand Co.: New York, NY, USA, 1946; Chapter 13.

21. Chih, W.C.; Kuan, C.H.; Li, J.S.; Sheng, H.H.; Jin, C.C. Wireless powering electronics and spiral coils for implant microsystem toward nanomedicine diagnosis and therapy in free-behavior animal. J. Solid-State Electron. 2012, 77, 93-100.

22. Mutashar, S.A.; Hannan, M.A.; Salina, A.S.; Hussain A. Inductive Coupling Links for Lowest Misalignment Effects in Transcutaneous Implanted Devices. Biomed. Tech. 2014, 59, 257-268.

23. Dielectric Properties of Body Tissues. Available online: http://niremf.ifac.cnr.it/tissprop/htmlclie/ htmlclie.htm (accessed on 27 June 2014).

24. Karacolak, T.; Cooper, R.; Topsakal, E. Electrical properties of rat skin and design of implantable antennas for medical wireless telemetry. IEEE Trans. Antennas Propag. 2009, 57, 2806-2812.

25. Jow, U.-M.; Ghovanloo, M. Modeling and Optimization of Printed Spiral Coils in Air and Muscle Tissue Environments. In Proceedings of the IEEE 31st Annual International Conference of the EMBS, Minneapolis, MN, USA, 2-6 September 2009; pp. 6387-6390.

26. Ulcek, J.L.; Cleveland, R.F., Jr. Evaluating Compliance with FCC Guidelines for Human Exposure to Radio Frequency Electromagnetic Fields; Office of Engineering and Technology. Federal Communications Commission: Washington, DC, USA.

27. Tutku, K.; Aaron, Z.H.; Erdem, T. Design of a Dual-Band Implantable Antenna and Development of Skin Mimicking Gels for Continuous Glucose Monitoring. IEEE Trans. Microw. Theory Tech. 2008, 56, 1001-1008.

28. An Internet Resource for the Calculation of the Dielectric Properties of Body Tissues in the Frequency Range $10 \mathrm{~Hz}-100 \mathrm{GHz}$. Italian National Research Council, Florence, Italy, Institute for Applied Physics. Available online: http://niremf.ifac.cnr.it/tissprop/\#appl (accessed on 27 June 2014). 
29. Christ, A.; Kainz, W.; Hahn, E.G.; Honegger, K.; Zefferer, M.; Neufeld, E.; Rascher, W.; Janka, R.; Bautz, W.; Chen, J.; et al. The virtual family-development of surface-based anatomical models of two adults and two children for dosimetric simulations. Phys. Med. Biol. 2010, 55, 23-38.

(C) 2014 by the authors; licensee MDPI, Basel, Switzerland. This article is an open access article distributed under the terms and conditions of the Creative Commons Attribution license (http://creativecommons.org/licenses/by/3.0/). 